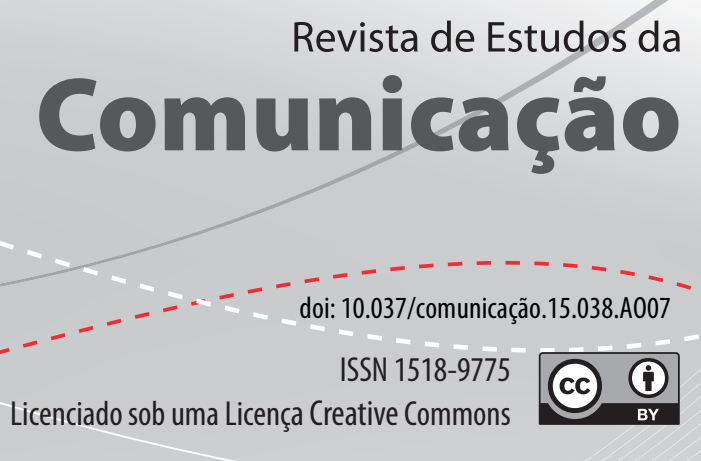

\title{
Abordagens conceituais sobre o cenário midiático contemporâneo: das Indústrias Culturais às Redes Digitais ${ }^{1}$
}

\section{Conceptual approaches of the contemporary scene: the cultural industries to digital networks}

\section{Dostoiewski Mariatt de Oliveira Champangnatte ${ }^{[a]}$, Marcus Alexandre de Pádua Cavalcanti ${ }^{[b]}$}

${ }^{[a]}$ Pós-Doutorando em Comunicação Social, Professor Pesquisador do Programa de PósGraduação Interdisciplinar em Letras e Ciências Humanas da Universidade do Grande Rio (Unigranrio), Duque de Caxias, RJ, e-mail: dostoiewski.tico@gmail.com

\footnotetext{
Este trabalho foi apresentado no III Congresso Internacional Interdisciplinar em Sociais e Humanidades, em outubro de 2014, Salvador, BA. O resumo do mesmo, até a data de envio deste artigo para Revista Estudos da Comunicação, ainda não foi publicado nos anais do congresso. $O$ texto do presente artigo passou por diversas modificações, sugeridas no congresso citado e decididas também pelos autores, tanto em termos de conteúdo, título e resumo.
} 


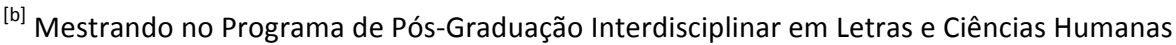
da Universidade do Grande Rio (Unigranrio), Duque de Caxias, RJ, e-mail: marcus_nathan1203@hotmail.com

\section{Resumo}

Este trabalho apresenta uma análise do heterogêneo cenário midiático contemporâneo a partir de abordagens conceituais que abrangem desde a discussão de práticas de meios de comunicação tradicionais, que fazem parte de indústrias culturais, à constituição e dinâmica das redes digitais. Considera-se o cenário midiático contemporâneo como heterogêneo pela existência concomitante de práticas comunicacionais tradicionais, em que há a existência de um, ou poucos, emissores produzindo/distribuindo conteúdos para diversos receptores, em que essa relação é estanque. E pela existência de práticas horizontais, nas redes digitais, em que há a quebra da relação unidirecional emissor-receptor e todos podem ser agentes e interagir na produção/recepção de conteúdos em processos dinâmicos. As abordagens conceituais referem-se, principalmente, aos conceitos de indústria cultural e hegemonia, evidenciando a contemporaneidade desses para a análise de meios de comunicação tradicionais. E aos conceitos de rizoma e contra-hegemonia, para análise da constituição e funcionamento das redes digitais e das práticas possíveis de resistência às formas tradicionais de comunicação.

Palavras-chave: Cenário Midiático Contemporâneo. Indústria Cultural. Redes Digitais. Hegemonia. Contra-Hegemonia.

\section{Abstract}

This paper presents an analysis of the heterogeneous contemporary mediascape from conceptual approaches ranging discussion of practices of traditional media, which are part of cultural industries, the formation and dynamics of digital networks. The contemporary media landscape as heterogeneous by concomitant existence of traditional communication practices, where there is the existence of one, or few, emitters producing/distributing content to multiple receivers, where this ratio is considered to be watertight. And the existence of horizontal practices in digital networks, where there is a breach of unidirectional relationship transceiver can all be agents and interact in the production/reception of content in dynamic processes. The conceptual approaches refer to the concepts of hegemony and cultural industry, highlighting the contemporaneity of these for the analysis of traditional media. And the concepts of rhizome 
and counter-hegemony to analyze the formation and operation of digital networks and the possible practices of resistance to traditional forms of communication.

Keywords: Contemporary Media Scenario. Cultural Industry. Digital Networks. Hegemony. Counter-Hegemony

\section{Introdução}

O debate sobre o papel das indústrias culturais nas sociedades contemporâneas pode ser renovado com o advento das tecnologias de informação e comunicação, sendo possível observar mudanças na produção/distribuição de conteúdos com o uso e a difusão dessas tecnologias. As indústrias culturais - televisão, jornais, rádios, impressos - empregam meios informativos utilizados nas esferas pública e privada e atuam produzindo/distribuindo conteúdos para as massas. A comunicação de massa, segundo Camponez (2002), é entendida como um tipo de comunicação em que a mensagem é transmitida de um centro emissor para uma "pluralidade de indivíduos receptores" (p. 76). E, por sua estrutura, pode se tornar uma forma unidirecional de transmissão de informações que tende a ser hegemonicamente, autoritária e vertical.

Diferentemente dessa estrutura, as redes digitais permitem estabelecer processos bidirecionais, em que os receptores também podem se tornar agentes emissores, aumentando a possibilidade efetiva de ocorrência de fenômenos comunicativos de forma rizomática ${ }^{2}$. O território digital cria uma zona dentro de outros territórios em que é possível acessar, produzir e distribuir informação, de maneira autônoma, estabelecendo redes colaborativas e processos comunicativos mais complexos.

$\mathrm{Na}$ atualidade, nota-se a existência concomitante de práticas tradicionais das indústrias culturais e práticas realizadas nas redes digitais por uma infinidade de pessoas de forma horizontal, em que todos podem emitir e receber conteúdos. Nota-se também a entrada de alguns conglomerados das indústrias culturais na Internet com objetivos atrelados, ou não, a suas práticas em meios tradicionais. Diante desse cenário heterogêneo, este trabalho se propõe discutir alguns concei-

\footnotetext{
Rizoma é um conceito utilizado por Deleuze e Guatarri (1995), nas ciências sociais, a partir de uma apropriação de um conceito da botânica, área da biologia que estuda as plantas. Nessa área, rizoma refere-se a um tipo de caule que algumas plantas verdes possuem que cresce horizontalmente. Deleuze e Guattari (1995) apropriaram-se desse conceito para explicitar fenômenos sociais nos quais não se determina um começo ou fim, os fenômenos estão sempre no meio, imbuídos de outros fenômenos, em um intermezzo, sem uma causa definida ou consequência pré-estabelecida.
} 
tos que permeiam tal cenário, como a indústria cultural, a hegemonia/contrahegemonia midiática e a concepção rizomática e horizontal dos processos possíveis nas redes digitais. Com o objetivo de compreender e discutir esse cenário heterogêneo, mas também de estimular relações com as mídias e práticas midiáticas mais críticas e descentralizadas.

\section{Práticas midiáticas contemporâneas: Indústrias Culturais, Hegemonia e Contra-hegemonia}

Nos tempos atuais, a família, a escola, o Estado, a religião e o trabalho não podem ser mais analisados e interpretados sem levar em conta as práticas midiáticas e as recepções/apropriações de seus conteúdos. As mídias exercem um papel fundamental na sociedade contemporânea devido ao seu poder de penetração material e simbólico no cotidiano das pessoas, tornando-se plausível, e até mesmo necessário, pensar a cultura e as ações sociais relacionando-as às mídias. A maioria dos conglomerados midiáticos globais está nas mãos de grandes empresas que veiculam informações e conteúdos de acordo com seus interesses econômicos e parcerias ideológicas. Entre esses conglomerados estão estúdios, produtoras, distribuidoras e exibidoras de filmes, gravadoras de discos, editoras, TVs abertas e pagas, emissoras de rádio, revistas, jornais, portais on-line, agências de publicidade e marketing, telefonia celular e agências de notícias (MORAES, 2004).

Os estudos dos meios de comunicação atrelados a questões econômicas, políticas e sociais tiveram, inicialmente, grande contribuição de dois pesquisadores, Adorno e Horkheimer (1985), que, a partir de uma abordagem interdisciplinar do marxismo, criaram o termo/conceito indústria cultural. Adorno (1977) informa que ele e Horkheimer empregaram o termo indústria cultural, pela primeira vez, no livro Dialética do Esclarecimento, publicado em 1947, após abandonarem a expressão cultura de massa que utilizavam em seus esboços. $O$ abandono de tal expressão se justifica porque cultura de massa pode dar a entender que se está analisando uma cultura produzida por uma massa, por um povo. Quando, na verdade, os autores queriam era denunciar a cultura imposta ao povo e, assim, tem-se que indústria cultural é radicalmente definida como uma expressão distinta daquela:

Em nossos esboços tratava-se do problema da cultura de massa. Abandonamos essa última expressão para substituí-la por 'indústria cultural', a fim de excluir de antemão a interpretação que agrada aos advogados da coisa; estes pretendem, com efeito, que se trata de algo como uma cultura surgindo espontaneamente das próprias massas, em suma, da forma contemporânea da arte popular. Ora, dessa arte a indústria cultural se distingue radicalmente. 
Ao juntar elementos de há muito correntes, ela atribui-lhes uma nova qualidade. Em todos os seus ramos fazem-se, mais ou menos segundo um plano, produtos adaptados ao consumo das massas e que em grande medida determinam esse consumo (ADORNO, 1977, p. 287).

Dessa forma, a expressão indústria cultural estaria associada não somente aos meios de comunicação, mas também à produção industrial de bens e serviços culturais para as massas. E sua função principal consiste em oferecer o que é vendável, o que tem mercado para ser consumido e o consumidor como objeto de lucro. Com a amplitude da definição do conceito de indústria cultural, cunhado por Adorno e Horkheimer (1985), pode-se afirmar que o termo é bastante contemporâneo e aplicável a análises de práticas sociais que envolvem os grandes conglomerados de comunicação.

Os meios de comunicação de massa configuram-se, ainda, como fortes colaboradores da formação do senso comum na esfera pública, dada as suas estruturas verticais e centralizadas, sob o comando de poucos emissores e distribuindo conteúdos para uma grande massa de receptores. E como os grandes meios de comunicação estão nas mãos de empresários, e muitas vezes com parcerias com o Estado, podem ser observadas intenções/práticas de hegemonização de pensamentos e consensos junto ao público.

Warnier (2000), em uma análise do desenvolvimento da aplicabilidade do conceito de indústria cultural, forneceu um panorama de comparação deste com culturas ditas tradicionais, alheias às mídias. $O$ autor aponta que foi preciso esperar que o conceito de indústria cultural passasse a ser utilizado, no final dos anos 1970, para que se pudessem vislumbrar questões interdisciplinares relativas às práticas dos meios de comunicação e suas relações com manifestações culturais já existentes, como a música, a fotografia e até mesmo a cultura oral. Warnier (2000) também aponta que as indústrias culturais, estruturalmente,

necessitam de grandes meios financeiros; utilizam técnicas de reprodução em série; trabalham para o mercado (ou mercantilizam a cultura); são baseadas em uma organização do trabalho do tipo capitalista (transformam o criador em trabalhador e a cultura em produtos culturais) (p. 27-28).

A partir dessas características, torna-se viável fomentar reflexões complexas sobre as indústrias culturais, em que é possível salientar que estas são, portanto, antes de mais nada, atividades industriais que produzem e comercializam discursos, sons, imagens, artes e qualquer outra capacidade ou hábito adquirido pelo homem enquanto características da cultura. Diante disso, faz-se necessário elucubrar que os estudos feitos por Adorno e Horkheimer (1985) foram de total im- 
portância, não só para sua época, mas para os dias de hoje. Embora complexo, o conceito de indústria cultural é algo que faz parte do cotidiano e a sociedade atual é irremediavelmente o lar da indústria cultural. Neste trabalho, o que se propõe é a compreensão e a contextualização da indústria cultural para que seja possível se pensar em alternativas à comunicação hegemônica.

O conceito de hegemonia, proposto por Gramsci, é bastante relevante para análises dos sistemas político, econômico e social, como também oferece uma boa base para o estudo das práticas midiáticas imbricadas por tais sistemas. Para Gramsci (2002), a hegemonia corresponde à liderança cultural e ideológica de uma classe sobre as demais, pressupondo a capacidade de um bloco histórico (aliança de classes e frações de classes, duradoura e ampla) dirigir moral e culturalmente, de forma sustentada, toda a sociedade. Segundo Moraes (2009, p.35), a hegemonia "tem a ver com disputas de sentido e entrechoques de visões de mundo, bem como com mediações de forças em determinado contexto histórico". Um processo hegemônico, portanto, não pode ser percebido como algo estanque e imposto para sempre, pois como afirma Fairclough (2001)

a hegemonia é o poder sobre a sociedade como um todo, de uma das classes economicamente definidas como fundamentais em aliança com outras forças sociais, mas nunca atingido senão parcial e temporariamente, como um 'equilíbrio instável' (p. 122).

Por ser uma categoria dinâmica, a hegemonia pressupõe negociações, compromissos e renúncias por parte do grupo dirigente que se pretende hegemônico. Para Gramsci (2002), a hegemonia não pode ser garantida sem desconsiderar demandas mínimas da classe dominada, sendo fundamental a classe dirigente saber ceder e saber realizar sacrifícios no intuito de preservar esse instável equilíbrio de forças. Ainda segundo Gramsci, a conservação da hegemonia

pressupõe indubitavelmente que sejam levados em conta os interesses e as tendências dos grupos sociais sobre os quais a hegemonia será exercida, que se forme um certo equilíbrio de ordem econômico-corporativa, isto é, que o grupo dirigente faça sacrifícios de ordem econômico-corporativa (p. 47).

As indústrias culturais buscam, em suas práticas, hegemonizar valores e sentidos junto aos receptores, sendo que tais valores podem estar ligados às suas estratégias econômicas, como também ideológicas, estabelecendo, assim, parcerias com diversos segmentos sociais, tanto privados como estatais. Os grandes conglomerados midiáticos se empenham em manter realidades que Ihes são benéficas e lucrativas e, para isso, aprisionam e sincronizam os seus espectadores e os 
deixam inertes a seus controles, tornando-os marionetes dos seus espetáculos. Hegemônicos na defesa de seus interesses, os conglomerados manipulam fatos sociais e os transformam, muitas vezes, em uma realidade falsa, mas crível, para os espectadores.

Como dito, a hegemonia não existe passivamente como forma de dominação, ela se renova continuamente, recria-se, defende-se, modifica-se e sofre uma resistência continuada e desafiante, tal resistência foi denominada, por Gramsci (1995), de contra-hegemonia. A função primordial de uma ação contrahegemônica é a de fazer com que a sociedade reflita, pense e seja dona de suas próprias escolhas de acordo com a sua consciência crítica. Para tanto, a convergência ideológica, política e cultural, na sua totalidade, é condição determinante para consolidar a contra-hegemonia.

Segundo Gramsci (1995), uma força contra-hegemônica só pode ser reconhecida como tal na medida em que consegue ultrapassar a espontaneidade do movimento que contribui com a capacidade de modificar e alterar uma dada estrutura social. Por exemplo, para quebrar as amarras hegemônicas da mídia tradicional, que pensa somente em seus próprios interesses e no consumo, é preciso que haja mais mídias contra-hegemônicas. Essas, por sua vez, têm de estar dispostas a alterar o cenário e buscar saídas democráticas e de participação popular, a partir de iniciativas como rádios e televisões comunitárias, imprensas alternativas e o acesso à livre circulação das informações na Internet, por exemplo. Para Góes (2007, p. 13)

dentro de uma leitura gramsciana, o ciberespaço na atualidade seria o ambiente onde as idéias contra-hegemônicas dos movimentos sociais encontram instrumento, divulgação e penetração na sociedade civil para exercer a sua luta. A sua importância estaria na ruptura da unidirecionalidade da comunicação; a pluralidade e diversidade de informações e pontos de vistas que a Web oferece; as novas possibilidades do público terem de verificar, direta ou indiretamente, a veracidade da informação que está recebendo, e de tomar sua própria decisão.

A Internet, portanto, pode permitir processos de comunicação alternativos aos grandes conglomerados, em que receptores podem ser emissores e receptores ao mesmo tempo, criando suas próprias plataformas comunicacionais. Isso não quer dizer que os conglomerados não estejam na Internet, pelo contrário, suas estratégias caminham cada vez mais para a web, porém, os espaços oferecidos pela Internet são infinitos, permitindo mobilizações alternativas que antes eram raras nos meios de comunicação tradicionais.

É válido ressaltar que Gramsci (2001) refletiu sobre o principal meio de comunicação de sua época - a imprensa. “A arte da imprensa revolucionou todo o 
mundo cultural, dando à memória um subsídio de valor inestimável e permitindo uma extensão inaudita da atividade educacional" (p. 67). Ele não teve tempo de vida para aquilatar a evolução dos modernos meios de comunicação no século XX, entretanto, ainda no início da década de 1930, observava que a imprensa escrita já sofria a concorrência de outros veículos, como o da comunicação falada. Nos Cadernos do cárcere, há a seguinte e expressiva observação sobre mutações que começavam a ocorrer na mídia de então, graças ao avanço técnico e às tecnologias que despontavam

Também hoje a comunicação falada é um meio de difusão ideológica que tem uma rapidez, uma área de ação e uma simultaneidade emotiva enormemente mais amplas do que a comunicação escrita (o teatro, o cinema e o rádio, com a difusão de alto-falantes nas praças, superam todas as formas de comunicação escrita, desde o livro até a revista, o jornal, o jornal-mural) (GRAMSCI, 2001, p. 67).

Gramsci (2001) também apontou que os meios de comunicação estavam sendo utilizados como estratégicas hegemônicas do Estado, muitas vezes em parceria com setores privados da sociedade de interesses ideológicos comuns aos seus. Nesse sentido, também apontou usos contra-hegemônicos dos meios de comunicação, como os jornais impressos e manifestações da comunicação falada, produzidos e liderados pela classe trabalhadora.

Diante dos apontamentos de Gramsci e das apropriações contemporâneas de seus conceitos por Góes (2007), pode-se afirmar que o papel principal da mídia contra-hegemônica deveria ser o de lutar contra o poder e controle social hegemônico, como, por exemplo, a partir de iniciativas que estimulem a cobrança das políticas públicas sociais e que motivem o cidadão a se tornar um sujeito crítico e participante ativo da comunicação, com o intuito de transformar realidades. 0 cenário contra-hegemônico contemporâneo, a partir da Internet, por exemplo, poderá se transformar em um espaço de debates e de apoio ao movimento de ideias que estimulem a informação e a reflexão sobre os mecanismos e instrumentos de dominação.

\section{Redes Digitais: perspectiva rizomática e processos horizontais}

Com os avanços tecnológicos do último século, podem-se observar significativas modificações nas formas de interação humana, principalmente, por meio da proliferação dos das mídias digitais. Estas passaram a alterar exponencialmente a comunicação mundial por intermédio não mais exclusivo dos veículos de comunicação de massa, como impressos, rádios e televisões, mas, agora, pautados pela 
crescente disponibilidade de telefonia móvel, Internet banda larga, satélites e toda a tecnologia digital de grande velocidade.

Nesse viés de análise tecnológica, Marshall McLuhan (1994) atribuía à mídia um papel ativo nos processos de transformação de toda estrutura do social, em que "as sociedades sempre foram influenciadas mais pela natureza dos media, através dos quais os homens comunicam, do que pelo conteúdo da comunicação" (p. 74). A partir dessa perspectiva, nota-se a importância estrutural do surgimento de uma nova tecnologia da comunicação na sociedade, pois ela altera não só a forma de se perceber, armazenar e comunicar fatos, mas também interfere nas formas de organização da própria sociedade. Na atualidade, por exemplo, os crescimentos das redes mundiais de comunicação estão sendo incorporadas ao cotidiano das pessoas e passando a mediar novas interações sociais.

As novas tecnologias da comunicação permitiram um maior e mais acessível fluxo de informação. Especialmente nas duas últimas décadas, com o crescimento da internet e das telecomunicações, não só as expectativas em relação à democratização cresceram, como a tensão entre o micro e o macro (entre o público e o privado) tornou-se cada vez mais presente na sociedade, por meio da comunicação em rede sem fronteiras, que leva espaços individuais ao chamado espaço-mundo, com diferentes produtores de informação e conteúdo, sendo cada indivíduo um emissor em potencial (AGNEZ, 2012, p. 38).

É importante perceber que a comunicação, nessa nova conjuntura, não pode mais ser pautada apenas no paradigma clássico do emissor e receptor de mensagens, como também as novas tecnologias passam a ter um novo papel social. André Parente (2004) aponta que a contemporaneidade é o momento em que as tecnologias de informação e da comunicação passam a ter um papel crucial na nova ordem mundial e que as redes são, a um só tempo, uma espécie de paradigma e de personagem principal das mudanças em curso. O funcionamento das redes se difere das práticas da indústria cultural porque não possuem centros ou organização centralizadora, seja estatal ou privada. Os agrupamentos ou conexões de indivíduos se dão em diversas direções e sem nenhum critério além das intenções dos indivíduos, "aqui a circulação de informações não obedece à hierarquia da árvore (um-todos) e sim a multiplicidade do rizoma (todos-todos)" (LEMOS, 2008, p. 68).

Nessa nova configuração rizomática, existe a possibilidade do sentido todostodos, alterando os papéis clássicos do modelo emissor-receptor. Pode-se afirmar, também, que no paradigma de comunicação em rede é incorporada a prática da informação em tempo real, de maneira multidirecional. Isso vem modificando a 
estrutura de produção e difusão da informação e, diante disso, Lemos (2006) propõe três categorias/explicitações que regem essa nova estrutura. A primeira delas refere-se à liberação do polo da emissão, possibilitando, assim, a multiplicação de agentes emissores e a quebra de monopólios de elaboração da informação. A segunda diz respeito ao princípio da conexão generalizada, que é a participação e colaboração de pessoas nos conteúdos. E a terceira está relacionada à reconfiguração da paisagem comunicacional, sendo que reconfiguração refere-se à ideia de modificação das estruturas sociais, das instituições e das práticas comunicacionais. É válido apontar que a nova paisagem comunicacional não aniquila o poder e a força dos meios de massa da indústria cultural, eles coexistem, porém, a nova paisagem pode permitir a reconfiguração das formas de produção e da circulação de informação.

Como se percebe, quando se pensa na comunicação em redes, qualquer pessoa pode produzir textos, mensagens e informações e publicá-las na Internet, tornando-a acessível a todos aqueles que se conectam a ela. Lévy (2003, p. 209) afirma que "como dizia um consultor americano a um dirigente da IBM, uma criança encontra-se aí, em situação de igualdade com uma multinacional", pois o rizoma pressupõe a inexistência de hierarquias ou centros.

Nessa mesma perspectiva, Amadeu (2009) destaca a importância da observação das estruturas das redes, primeiro porque elas

têm um desenho e uma geometria diferenciados. Segundo, porque as redes são flexíveis e é provável que o grau de flexibilidade interfira na comunicação; Terceiro, porque as características de uma rede digital, por exemplo, a organização, as regras de conectividade, o desenho, podem influenciar a formatação dos conteúdos comunicados, a velocidade de transferência das informações e, até mesmo, os próprios conteúdos (AMADEU, 2009, s/n).

Como exemplo, têm-se aqueles que constroem páginas, perfis na rede e expõem seus pontos de vistas, tanto sobre um determinado assunto, quanto sobre sua própria vida. Quando alguém escreve algo em um blog, por exemplo, mostra ali sua opinião, seu ponto de vista sobre determinado assunto. Quando alguém cria um perfil em uma rede social, posta suas melhores fotos, seus melhores links, suas melhores frases, aquilo que ela pensa de si, e da sociedade na qual está inserida. Lévy (2003, p. 214) afirma que "qualquer um terá a sua página, o seu mapa, o seu site, o seu ou os seus pontos de vista. Cada um se tornará autor, proprietário de uma parcela do ciberespaço". Entretanto, essas páginas, sites e mapas dialogam, interconectam-se e confluem por meio de canais móveis e labirínticos, o que Lévy (1999) também denomina de rizoma 
Na web, tudo se encontra no mesmo plano. E, no entanto tudo é diferenciado. Não há hierarquia absoluta, mas cada site é um agente de seleção, de bifurcação ou de hierarquização parcial. Longe de ser uma massa amorfa, a web articula uma multiplicidade aberta de pontos de vista, mas essa articulação é feita transversalmente, em rizoma, sem o ponto de vista de Deus, sem uma unificação sobrejacente (p. 160).

Verifica-se, então, que na comunicação rizomática, há uma dimensão descentralizada e cada vez menos hierarquizada e, nesse sentido, no contexto da Internet, não se interessaria criar modelos, propor caminhos, impor soluções, não se trataria de buscar a complexidade de uma suposta unidade perdida, mas viabilizar conexões horizontais descentralizadas. Diferentemente dos meios de comunicação de massa da indústria cultural, que correspondem a um modelo fundado na visão arborescente que, diferentemente do modelo rizomático, possui formato hierárquico, elege mecanismos de delimitação de fronteiras e mapeia os canais de circulação de pessoas e coisas em um território estratificado na forma de um espaço estriado ${ }^{3}$. O modelo arborescente, como uma árvore, possui um tronco principal que se segmenta em diversos outros troncos. Tal metáfora, a partir de Deleuze e Guattari (1995), aplica-se à indústria cultural na qual existe uma, ou poucas, organizações principais que controlam todos os outros segmentos e processos numa perspectiva vertical, de emissor para receptores.

Ao contrário da metáfora da árvore, o rizoma não é modelo, mas processo imanente descentralizado, sem chefe ou estrutura administrativa superior, em que os canais de comunicação não são preexistentes e nos quais todos os elementos são intercambiáveis. Deleuze e Guattari (1995) propuseram alguns princípios relacionados à constituição/funcionamento do rizoma, que permitem vislumbrar ainda mais a complexidade desse conceito. Inicialmente, o primeiro e segundo princípios de conexão e heterogeneidade - significam que qualquer ponto de um rizoma pode ser conectado com qualquer outro, "um rizoma não cessaria de conectar cadeias semióticas, organizações de poder, ocorrências que remetem às artes, às ciências, às lutas sociais. Uma boa cadeia semiótica é como um tubérculo que aglomera atos muito diversos" (p. 16). Ou seja, não há dicotomizações nem proce-

\footnotetext{
Deleuze e Guattari (1995) propõem uma distinção entre dois tipos de espaço: o liso e o estriado. No espaço liso do controle, as instituições volatizam-se, perdendo suas fronteiras e mantendo entre si uma relação de modulação num continum regulador. Já o espaço estriado é abordado, segundo os autores, como aquele demarcado por fronteiras e hierarquias no interior do qual as instituições exercem poder. Espaço delimitado, fixo, distinto, ao contrário do espaço liso, que funciona a partir de redes flexíveis moduláveis. Deleuze e Guattari deixam claro que esses dois espaços podem interpenetrar-se e transformar-se um no outro, o que implica dizer que esses espaços convivem lado a lado. $\mathrm{Na}$ verdade, pode também se dizer que a comunicação em redes não elimina a comunicação de massa da indústria cultural, e que ambas convivem lado a lado na contemporaneidade.
} 
ssos hierárquicos, como em uma árvore, e a heterogeneidade se desenvolve no bojo das conexões, visto que, ao se conectar com qualquer ponto, as características produzidas acabam por serem diversas.

O terceiro princípio - de multiplicidade - afirma que o rizoma não mantém relação com o uno, pois em um rizoma encontram-se somente linhas e não pontos ou posições como numa estrutura, numa árvore. Assim, na instância da multiplicidade, não faz sentido se falar de sujeito ou de objeto, já que se trata aqui de grandezas e determinações que se expandem de acordo com seus agenciamentos. "Um agenciamento é precisamente este crescimento das dimensões numa multiplicidade que muda necessariamente de natureza na medida em que ela aumenta suas conexões" (p.17). O quarto princípio - de ruptura a-significante - considera que um rizoma pode ser rompido e quebrado em um lugar qualquer, mas, também, pode retomar-se a partir de suas próprias linhas ou agrupando outras. Cada vez que há uma ruptura no rizoma, as linhas segmentares explodem em uma linha de fuga, mas estas linhas de fuga são parte do rizoma, ou seja, as linhas não param de remeter umas às outras. Nesse sentido, o quinto e o sexto princípios - de cartografia e de decalcomania - podem ser interpretados nesse contexto, como o refazer do já feito.

O mapa rizomático é feito de conexões, é aberto, "desmontável, invertível, susceptível de receber modificações constantes" (p. 32). Isso significa que os rizomas não podem ser modelados, pois eles são sempre esboços incompletos e abertos. Para tanto, os autores propõe a possibilidade de cartografia dos processos, em que é possível se perceber as constantes mudanças do mapa que está sempre se reconfigurando por meio de seus movimentos. Ou seja, os mapas rizomáticos se fazem e se desfazem instantaneamente e, por isso, um rizoma não pode ser justificado por nenhum modelo estrutural.

De acordo com Pinheiro e Silva (2008), o rizoma, utilizado como metáfora para as redes, constitui-se de nós interligados, que conectam qualquer ponto independentemente da sua natureza. Além disso, não é feito de unidades e sim de dimensões, não tem começo nem fim, mas possui um meio pelo qual cresce e se estende. Para os autores, o conceito de rizoma reforça o sentido de horizontalidade das formas de comunicação e organização sociais, opondo-se ao sentido hierárquico que seu crescimento vertical remete.

Pensando a comunicação como rizoma e não como árvore, pode-se observar que as informações tendem a soar como linhas que se misturam, como teias de possibilidades, multiplicidade de nós, de conexões e de interconexões. Se a árvore não estimula e não permite o diálogo, o rizoma, ao contrário, estimula os encontros e as conjunções. E se a imagem da árvore implica num sistema fechado e unitário, a imagem do rizoma, por sua vez, implica num sistema aberto e múltiplo, pois não é composta de um percurso apenas, mas inúmeros percursos, com pontos 
de partida e pontos de chegada distintos. O que não inviabiliza encontros, pelo contrário, os possibilita, os promove e os estimula.

\section{Considerações finais}

Neste trabalho, observou-se que o debate sobre o papel da indústria cultural e da mídia, nas sociedades contemporâneas, é renovado com o advento das redes digitais de comunicação, em que o modelo de redes promove uma série de mudanças e disputas. $\mathrm{O}$ modelo rizomático das novas mídias e o modelo arborescente da indústria cultural existem concomitantemente, pois, como já abordado, a indústria cultural está englobando a Internet em suas atividades. Percebe-se a complementaridade entre diferentes meios de comunicação, a proliferação da oferta midiática e a ampliação dos usos possíveis feitos para cada um deles ou, cada vez de forma mais incisiva, entre eles e de forma combinada. Assim, pode-se dizer que o modelo de comunicação massiva se mantém e pode ser identificado em lógicas presentes na própria rede, mas é impactado por um modelo de comunicação que se baseia, entre outros aspectos, na relação entre as mídias, em um espaço de participação maior do público na produção da informação e de autonomia no processo comunicativo.

As novas tecnologias de comunicação e informação poderão ser vetores de agregação social, de vínculo comunicacional e de recombinações de informações das mais diversas sobre formatos variados, evidenciando muito bem o movimento de recombinação cultural em um território eletrônico (LEMOS, 2003). A conexão em rede instaura uma estrutura midiática ímpar na história da humanidade, na qual, pela primeira vez, qualquer indivíduo pode produzir e publicar informação em tempo real, sob diversos formatos e modulações, adicionar e colaborar em rede com outros, inclusive reconfigurando a indústria cultural. Trata-se de crescente troca e processos de compartilhamento de diversos elementos da cultura a partir das possibilidades abertas pelas tecnologias eletrônico-digitais e pelas redes telemáticas contemporâneas. Pode-se dizer que, atualmente, se está imerso em uma paisagem audiovisual dupla, na qual dois sistemas comunicacionais amplos, complementares e, muitas vezes, antagônicos, coexistem, oferecendo maior pluralidade infocomunicacional. O modelo arbóreo da indústria cultural, caracterizado pelas mídias tradicionais, e o modelo rizomático, caracterizado pelas mídias digitais, redes telemáticas e processos recombinatórios de conteúdo informacionais emergentes.

Enfim, este trabalho procurou tecer considerações sobre a indústria cultural e as novas mídias, no intuito de vislumbrar que tais conceitos representam estruturas que existem concomitantemente na contemporaneidade, cada uma com um 
modo de funcionamento diferenciado. O primeiro, voltado ao lucro e a hegemonização das massas e o segundo, permeado e produzido por conglomerados comunicacionais, mas também por todos. Encerra-se este trabalho incitando práticas horizontais, contra-hegemônicas, nas novas mídias, que produzam novos conteúdos e que questionem a indústria cultural, esta que, por sua vez, sorrateiramente, em suas estratégias, já está tentando dominar as novas mídias, buscando hegemonizar, ali também, seus conteúdos e ideologias.

\section{Referências}

ADORNO, T. HORKHEIMER, M. A Indústria cultural: o esclarecimento como mistificação das massas. In: Dialética do esclarecimento - fragmentos filosóficos. Tradução: Guido Antônio de Almeida. Rio: Zahar, 1985.

ADORNO, T. A indústria cultural. In: $\mathrm{COHN}, \mathrm{G}$. (Org.). Comunicação e indústria cultural: leituras de análise dos meios de comunicação na sociedade contemporânea e das manifestações da opinião pública, propaganda e cultura de massa nessa sociedade. 5. ed. São Paulo: Ed. Nacional, 1977.

AGNEZ, L. F. A convergência digital na produção da notícia. Natal: UFRN, 2012.

AMADEU, S. Arquiteturas em disputa: ativistas P2P e a indústria da intermediação. Revista de Economia Política de las tecnologias da información y comunicación, vol. 11. Aracaju, Eptic: 2009.

CAMPONEZ, C. Jornalismo de proximidade. Coimbra: Minerva, 2002.

DELEUZE, G; GUATTARI, F. Mil platôs: capitalismo e esquizofrenia. São Paulo: Ed. 34, 1995. v. 1.

DELEUZE, G; GUATTARI, F. Mil platôs: capitalismo e esquizofrenia. São Paulo: Ed. 34, 1995. v. 5.

FAIRCLOUGH, N. Discurso e mudança social. Brasília: Editora da UNB, 2001.

GRAMSCI, A. Os intelectuais e a organização da cultura. Rio de Janeiro: Civilização Brasileira, 1995.

GRAMSCI, A. Cadernos do cárcere. Rio de Janeiro: Civilização Brasileira, 2002 (v. 3).

GÓES, L. Contra-hegemonia e Internet: Gramsci e a Mídia Alternativa dos Movimentos Sociais. In: CONGRESSO DE CIÊNCIAS DA COMUNICAÇÃO DA REGIÃO NORDESTE, 9, Salvador, 2007. Anais do IX Congresso de Ciências da Comunicação da Região Nordeste. Salvador: Universidade Federal da Bahia, 2007. 
LEMOS, A. Cibercultura: Alguns pontos para entender a nossa época. In: LEMOS, A; CUNHA, P. (Orgs.). Olhares sobre a Cibercultura. Porto Alegre: Sulina, 2003.

LEMOS, A. Ciber-cultura-remix. In: ARAUJO, D. C. (Org.). Imagem (ir)realidade: comu- nicação e cibermídia. Porto Alegre: Sulina, 2006.

LEMOS, A. Cibercultura, tecnologia e vida social na cultura contemporânea. Porto Alegre: Sulina, 2008.

LÉVY, P. Cibercultura. São Paulo: Editora 34, 1999.

LÉVY, P. A Revolução contemporânea em matéria de Comunicação. In: MARTINS, F. (Org.). Para navegar no século XXI: tecnologias do imaginário e cibercultura. 3. ed. Porto Alegre: Sulinas/Edipucrs, 2003.

MCLUHAN, M. Os meios de comunicação como extensões do homem. São Paulo: Cultrix, 1994.

MORAES, D. A lógica da mídia no sistema de poder mundial. In: Revista de Economía Política de las Tecnologías de la Información y Comunicación, v. 6. Aracaju, Eptic: maio-agosto de 2004.

MORAES, D. A batalha da mídia: governos progressistas e políticas de comunicação na América Latina e outros ensaios. Rio de Janeiro: Pão e Rosas, 2009.

PARENTE, A. Tramas da Rede: Novas dimensões filosóficas, estéticas e políticas da comunicação. Porto Alegre: Sulina, 2004.

PINHEIRO, L. V.; SILVA, E. L. As redes cognitivas na Ciência da Informação brasileira: um estudo nos artigos científicos publicados nos periódicos da área. In: Ciência da Informação, v. 37. Brasília: IBCIT, 2008.

WARNIER, J.P. A mundialização da cultura. Bauru/SP: Edusc, 2000.

Recebido: $11 / 11 / 2014$

Received: $11 / 11 / 2014$

Aprovado: 20/11/2014

Approved: $11 / 20 / 2014$ 